\title{
'We are all just prisoners here of our own device': The moral challenge of balancing technology, work and capitalistic pursuits
}

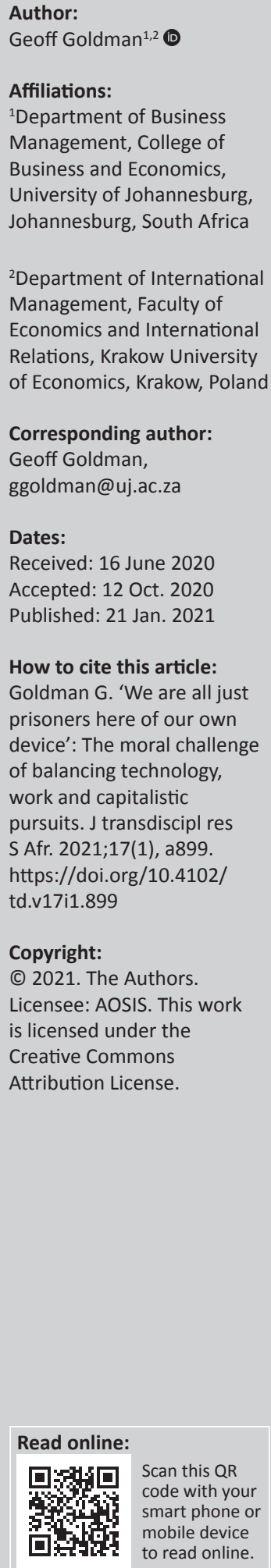

Although technological proliferation is a reality in a 4IR world, and has immense potential to increase the efficiency and quality of work, it is accompanied by workplace practices that there is no benchmark for. These practices have the potential to unsettle traditional work routines, traditional work/non-work boundaries, and to disturb peoples' work life balance irreparably. Against this backdrop, this paper explores the parameters of morally acceptable organisational practices in terms of usage and expectations of ICT's. Through adopting a Critical scholarly stance, this paper dialectically investigates the nature of work and the importance people associate with it, the ways in which technology impacts work and peoples' lives, and uncovers how technology enables control over labour in a capitalist society. The effect the current technological explosion has been far reaching and is effecting every sphere of life. As we try to make sense of $4 \mathrm{IR}$, we are also redefining our different contexts and the role technology and ICT play in each of these. We are noticing a definite blurring of spaces that, not too long ago, had distinct parameters.

Keywords: 4th Industrial Revolution; autonomy; capitalism; control; 'goods of work'; morality; technology; technology paradox.

\section{Introduction}

As we forge ahead into the 21st century, it is clear that the rate of technological proliferation is unrelenting and there are no indications that this proliferation is likely to slow down in the immediate future. ${ }^{1}$ The effect of this technology explosion has been far reaching and effects literally every sphere of life. The impact of technology, and especially information and communications technology (ICT), has reached our workplaces, our places of relaxation and our homes. ${ }^{2,3}$ As we try to make sense of the Fourth Industrial Revolution (4IR), we are also redefining our different contexts and the role of technology and ICT in each of these contexts. ${ }^{1,4}$ As we explore the capabilities and possibilities presented by technology and ICT in our workplaces and in our homes, we are noticing a definite blurring of spaces that, not too long ago, had distinct parameters. ${ }^{5}$ We take our work home, we take our entertainment to work, we are connected and within reach wherever we go.

Yet, just as we need to come to terms with the capabilities and possibilities that technology and ICT offer, so too, we need to come to terms with some of the realities these technologies have brought with them. The reality of cyberbullying and the triple-A nature of technology (Anywhere, Anytime, At the press of a button) imply that privacy has assumed a whole new meaning in the modern age. ${ }^{6}$ We are exposed to the world, even within the confines of our homes. The new social (media) convention is that messages must be answered, immediately. If this is not done, it is frowned upon. If we switch our devices off, we get ridiculed or reprimanded when we switch them back on again.

In much the same vein, vocational realities and expectations have also changed as technology and ICT have filtered into every sphere of our lives. ${ }^{7}$ Line managers feel it is acceptable to communicate with subordinates after hours, and to request tasks to be performed after hours. Very often these requests are accompanied by deadlines such as 'first thing in the morning' or 'by Monday morning'.

The question that inadvertently arises is, 'are emergent organisational practices and expectations associated with modern technology morally acceptable?' 
There can be no doubt that the technological proliferation has had definite advantages as far as workplace applications are concerned. ${ }^{8,9}$ The current coronavirus disease 2019 (COVID-19) pandemic is a prime example. During the 'lockdowns' imposed in many countries around the word, people were able to still fulfil their work duties from home, thereby keeping the economy going. Our technological advancements have enabled us to take the office with us. Wherever we are, our offices and workplaces are there too. This is a definite advantage for humankind as a whole, and is beyond question.

However, the question above delves into the issue of what is deemed acceptable within the parameters of this new technological reality. ${ }^{1,10}$ Of course, this depends on which side of the coin you are looking at. From the organisational perspective, such actions are warranted and even necessary to ensure organisational efficiency at all times. Yet, this organisational view forgoes any morally acceptable point of view, and it is purely an economically sensible point of view. It marginalises people's right to privacy, does not respect working hours and assumes that people are at the behest of the organisation on terms that the organisation has discretion over.

The objective of this article, therefore, is to ascertain where the parameters of morally acceptable organisational practices lie in our 4IR world. To this end, the article employs a critical dialectical approach to ultimately present an argument regarding people's current reality in a technology dominated world. Once these problematic areas are better understood, more amicable and pragmatic solutions to these issues could be sought.

To present an argument of what is morally acceptable as far as the usage and application of technology for organisational purposes is concerned, this article starts off by delving into the aspect of 'work' per se, and what intrinsic value work brings to people's lives. Next, the discussion will turn to the rise of technology, but more specifically to the paradoxes associated with technological proliferation. Then the discussion will premise that technology has become another capitalist mechanism to subjugate the working class and professional workers, and to exercise more control over them.

\section{The nature and importance of work}

Performing work in exchange for payment has become one of the main forms of social cooperation in modern societies. ${ }^{11}$ The overwhelming majority of people need to work in order to make a living through the wage gained in exchange of work performed. Yet, wages - or money alone is not the only benefit people derive from performing work. Apart from wages, people draw certain particular benefits or 'goods' from work, and this acts as a motivator to work. ${ }^{12}$ These 'goods of work' can also be seen as the ways in which work can be meaningful, both on a personal and at a societal level. ${ }^{12,13,14}$

The first of these 'goods' has to do with the idea that people strive to attain excellence, in one form or another, in their work. This is a regulative ideal which broadly translates to the accomplishment of certain things that are of importance to the individual. Murphy ${ }^{15}$ argues that achieving excellence embodies the nexus of intellect and practice - two elements central to Aristotle's conception of work. Thus, excellence can be seen as the culmination of conceptualisation and practice, which takes time to achieve. ${ }^{16}$ The individual therefore constantly focusses on what needs to be accomplished, and applies his or her intellect in novel ways over time through various iterations to not only accomplish what they have set their sights on, but also to accomplish it at or beyond a certain level of performance expectation. Thus, it can be concluded that excellence involves more than merely accomplishment of certain things, but rather implies mastery of these things. ${ }^{17,18}$ This mastery also implies the opportunity for individuals to develop their abilities in order to achieve excellence, which is an intrinsic motivator in itself. ${ }^{12}$

A further 'good' of work is an individual's need to contribute to society in some form or another. The context of paid work provides a natural setting for the pursuit of societal contribution, as individuals spend most of their time in this setting and because this context provides a platform for identifying what aspects of work can be transformed into social utility. ${ }^{12}$ Finding a link between daily work and the contribution it makes to the greater society is an essential source of deriving meaning from work for many individuals, and impacts positively job satisfaction, job engagement and ultimately job retention. ${ }^{19}$ Terkel $^{20}$ sums up the need to make a positive societal contribution as:

... the search for daily meaning as well as daily bread. (p. 11)

Another 'good' forthcoming from work is that work contributes to individuals' sense of community. ${ }^{12}$ According to Francis et al. ${ }^{21}$ :

... an individuals' feeling of belonging and contributing to a group and the individuals within that group, functioning together in a common belief that everyone's needs will be met through their commitment to the group and to one another. (p. 401)

This sense of community is not only derived from work, and most probably plays an important role in why people join specific interest groups such as sports clubs, hobby clubs and civil agencies. However, the sense of community forthcoming from paid work represents a specific experience in itself, as individual effort contributes to the effort of the collective in a context where most individuals spend the majority of their time and effort outside the family context. ${ }^{22}$ Gheaus and Herzog ${ }^{12}$ caution that organisational structure can play a role in the sense of 
community experienced by individuals. In this regard, the basic unequal power relations prevalent in organisations structured hierarchically according to conventional, capitalist canon, forthcoming from the 'legitimate' forms of authority built into and associated with it, ${ }^{23}$ often lead to situations where these relations are governed by power alone. This is because an individual employee is more reliant on the organisation to make a livelihood than the latter being reliant on the individual to realise a profit. Where these power imbalances become excessive, the feeling of community is diminished.

The final 'good' forthcoming from work is the recognition individuals receive for work, not necessarily from the organisation that employs them, but rather from peer groups, family, immediate community and society at large. People, therefore, also perform paid work for the social recognition they receive. As is the case with people's need to experience a sense of community, and most of the 'goods' of work introduced above, paid work is not the only source of social recognition, but as people spend a large amount of time in working, it provides the greatest amount of opportunity for gaining social recognition..$^{12}$ Social recognition - both inside and outside the organisation - is important to individuals as it serves as recognition for their achievements. ${ }^{24}$ Furthermore, social recognition is not only sought by individuals for the type of work they do, but also for the position they occupy within the organisational hierarchy, which stems from the prominence of work in modern, capitalist-orientated societies.

These 'goods' associated with work, as identified by Gheaus and Herzog, ${ }^{12}$ are neither mutually exclusive nor dependent on one another. For example, Albert Einstein worked in the Bern Patent Office in Bern whilst developing his Theory of Relativity, which he published in $1905 .{ }^{25}$ This was certainly not a job that provided him with a sense of community or social recognition. He aspired to a teaching post at a university and only took up the Patent Office job because he could not secure a teaching post. Yet, he used the opportunity to focus on his research - thus aspiring to achieve excellence - which came with the publication of four groundbreaking papers in 1905, of which his paper on the Theory of Relativity was one..$^{25}$ By 1909, Einstein was recognised as a prominent physicist and occupied the position of Associate Professor at the University of Zurich, thereby having achieved social recognition and a sense of community. However, as his work was mostly theoretical, he found an opportunity to contribute to society with his input on the Manhattan Project, which developed the first nuclear weapon and helped put an end to World War II. ${ }^{26}$ Although Einstein was a pacifist, he realised the threat to humanity posed by the Axis powers, and he was committed to doing his part in eliminating that threat. Thus, his contribution to society was not in the development of nuclear weapons, but rather in seeking to strive for a world that would be free from the dehumanising scourges of the Axis powers.
Furthermore, it needs to be emphasised that these 'goods' of work are also not absolutes, but rather are manifested in degrees. Thus, these 'goods' need to be conceptualised as continuums, with individuals occupying positions that reflect varying degrees of each 'good'. ${ }^{12}$

However, work is not always associated with good. The other side of the argument is also apparent, and paid work is also associated with many ills. Apart from monetary and material ills, such as insufficient wage, or the lack of benefits such as, inter alia, medical aid, pension or an annual bonus, many of the main ills associated with work are associated with the absence of the non-monetary 'goods' introduced above. Very seldom will people occupy a job which is totally devoid of the 'goods' associated with work for any discernible length of time. A job which is totally devoid of the 'goods' of work will soon feel arduous, compulsory, dull and repetitive. However, there are some ills of work that are not merely attributed to the absence of the 'goods' associated with work, but are rather forthcoming from the inability to ensure more common 'goods'. ${ }^{12}$ These more common 'goods' include respecting freedom and self-determination of individuals, respect for individuals' leisure time and free time, respect for the right of non-domination and ensuring the health of employees.

To ascertain what is morally acceptable in terms of organisational practices in the modern, technology-dominated world, it is imperative to understand how technology impacts the 'goods' associated with work and also how it impacts the more common 'goods' that filter through into the workplace, as sketched above. Our technological advancements certainly have the capability of positively contributing to the 'goods' associated with work. In terms of excellence, technology has a definite positive contribution to make. Architects and other design professionals rely on technology to aspire to perfection of their craft. Computerised software and rapid prototyping are indispensable tools of their professions, allowing far more detailed conceptualisation of their ideas. Rapid prototyping, for example, allows industrial designers to create a threedimensional rendition of their design ideas which can be refined into a final prototype. Communication technologies and the information available on the Internet have allowed academics, for example, to transform the way they teach and conduct research. In terms of teaching, academics can utilise blended learning, conduct on line assessments and be far more interactive with students than what was possible three decades ago.

However, the mere presence of technology does not ensure excellence on the part of the individual. Technology provides the possibility to achieve excellence, but the onus still rests upon the individual to take advantage of the possibilities offered by technology. Furthermore, it is crucial that the organisation provides technology in order for individuals to achieve excellence. It is obvious that the achievement of excellence is not only an intrinsic motivator for individual employees, but also a contributing factor for achieving 
maximum efficiency of the labour force. Technology is more than just a potential source of competitive advantage for an organisation, and it has also become an essential requirement. It is evident that technology has set certain minimum standards, and if organisations do not invest enough in technology to meet these minimum standards, they will not be able to compete on an equal footing with their competitors in the marketplace. In terms of technology, thus, it is definitely a contributing factor in individuals' attainment of excellence and contributes to this 'good' if the organisation has invested sufficiently in it, and on the correct type of technology necessary. One can therefore safely deduce that insufficient investment in technology, or investment in the wrong type of technology, will detract from individuals' ability to achieve excellence, turning this into an ill.

Technology also has a potential role to play in individuals' sense of contributing to society. Communication technology, social media and the Internet have caused an information explosion, and people interact with and provide feedback to organisations much more readily via social media. Thus, the organisation, and hence also those people that are employed by the organisation, come to hear about how their products and services have impacted people's lives in the broader community. This feedback, however, can be both positive and negative, and although negative feedback can detract from a sense of contributing to society, it could, at the same time, act as an impetus for corrective action. Furthermore, as new technologies lower production costs over time, social responsibility programmes become cheaper for the organisation, and more can be done for the upliftment of societies with available budgets. For example, think of solar powered geysers offered to low-cost housing projects. Whilst solar power was only accessible to more affluent societies a few decades ago, the technology is more advanced and much cheaper today, and less privileged communities are able to take advantage of this.

Social media and the Internet have a definite role to play in individuals' sense of community and belonging, as well as people's need for social recognition. Social media platforms, such as Facebook, Twitter and WhatsApp, are used by organisations to create formal communities that contribute to a sense of belonging amongst individuals. Furthermore, informal groups aimed at more social endeavours are also formed on these platforms by employees that contribute to this sense even further. These platforms also create avenues for social recognition. This can be formal, for example, where employees' achievements are posted on the organisation's Facebook page by the CEO, or informal, where individuals, for example, share a particular achievement or award with peers on a WhatsApp group.

However, the effects of technology on the more common 'goods' that filter into the organisational setting are more subtle. Attainment of these more common 'goods' seems to conflict with some of the canons of capitalism, and unregulated capitalist systems are therefore frequently accused of undermining the basic standards of justice and acting in an immoral fashion. ${ }^{27}$ For example, whilst organisations uphold basic standards of physical safety (more often than not prescribed by law), very little regard exists for psychological well-being of employees. Line managers seldom contemplate the effect that orders, requests, deadlines and messages will have on an individual's mental state. The hierarchical position line managers occupy legitimises these actions and subordinates are expected to accept these and deal with it irrespective of their moral positioning.

Furthermore, the seniority prescribed by the organisational hierarchy is very often extended outside the organisational setting, which disregards the right to non-domination. For example, when a subordinate meets his or her line manager in the queue at a bank, she might still refer to him as 'sir', or a line manager seeing a group of subordinates after work at a café walks over and dominates the conversation, displaying the same domineering behaviour as at work. Again, within the organisational setting these practices are justified as functions of seniority, which is questionable in itself, but outside the organisational setting this hierarchical relationship does not exist and should not be perpetuated.

Unfortunately, as much as it holds many benefits, as alluded to above, technology definitely has the propensity to compromise the basic conditions of a decent life. Social media platforms make it easier to communicate with fellow employees, but the 'faceless' nature of social media makes it easier to say things that people might be cautious of saying face-to-face. Thus, social media subjects subordinates not only to a barrage of communication, but very often this communication leads to unnecessary stress and psychological burden. Furthermore, if subordinates ignore the communication or turn devices off, the consequences could be dire.

The situation sketched above brings a couple of dilemmas to the fore. Firstly, technology creates an environment where personal time can seriously be encroached upon, as communication can take place anywhere and at any time. Secondly, technology enables misuse of the hierarchical power relations between line manager and subordinate in that requests to perform work outside of office hours are forthcoming. Very often, requests to perform a task 'by first thing in the morning' are sent the previous evening, which is morally questionable. Also, technology enables a situation where the hierarchical arrangement prevalent in the organisational setting transcends the boundaries of the organisation and finds its way into the personal and private lives of individuals. For example, an individual might occupy the position of a clerk in a financial institution performing many menial tasks at the request of his or her line manager, but in his or her private life he or she is a family person with two children. In his or her family capacity, he or she is the head of the household and the 
rock of the family. However, the advent of technology has seen requests for menial tasks and arduous errands continue after hours and over weekends. The final result is that the individual no longer feels like the head of his or her family. The organisational hierarchy has filtered into his or her private life, causing him or her to experience the same emotions that he or she associates with work at home. This is an unjust scenario, undermining that individual's ability to lead a decent life.

If one considers both the 'goods' associated with work and the common 'goods' that filter through into the workplace that have been expounded upon in this section, it becomes apparent that these factors provide individuals with a sense of finding meaningfulness in the work they do. This provides significance to the work people perform on a daily basis, which makes the mundane and routine 'going through the motions' of paid work all seem worthwhile, and provides the individual with a sense of being part of 'something bigger'.11,28 Meaningful work contributes positively to a meaningful life, ${ }^{29}$ which is an ideal every human being strives for. ${ }^{30,31}$ Thus, factors that detract from or erode meaningful work have a negative impact on trying to attain a meaningful life. ${ }^{11}$ It stands to reason that these should be avoided or eliminated at all cost.

It is the violation of especially the common 'goods' that filter into the workplace in the era of 4IR that is of special interest. It is not that technology itself is responsible for violating people's right to private and free time, and violating people's right to non-domination. People do that. But technology has provided people with the means to enact these moral injustices. Technology, thus, is the enabler for these things to occur. To illuminate this issue even further, the discussion now turns to the proliferation of technology, and certain paradoxes that have been forthcoming from this proliferation.

\section{Technological proliferation and technology paradoxes}

The latter part of the 20th century and the beginning of the 21st century have witnessed a spurt of unprecedented technological advancement that has filtered into every aspect of people's lives. Information and communications technologies especially have witnessed the birth of a 'triple-A' work culture, one where people are available 'Anytime, Anywhere, and At the press of a button', 1,6 also referred to as an 'Always On' culture. ${ }^{32}$ In 2019, cellular telephone networks were available to $97 \%$ of the world's population, with more than 8 billion cellular phone subscriptions and more than 4 billion Internet users. ${ }^{33}$ Furthermore, the ICT devices themselves have also increased vastly in versatility, allowing for a greater scope of tasks to be performed on them. This access to communication channels and unlimited connectivity at all times has witnessed work tasks being performed with greater efficiency and ease, thereby empowering individuals to perform daily work tasks with greater freedom and autonomy of movement. ${ }^{4}$

It is obvious that the technological proliferation we are experiencing in the 4IR has definite advantages, which cannot be denied. The advantages forthcoming from this era of increased technology availability and usage reported in the literature include increased access to information, which enables flexible work arrangements, ${ }^{1}$ and increased efficiency of communication, ${ }^{8}$ which contributes to a sense of professional competence and control, ${ }^{34}$ increased autonomy over the work performed ${ }^{2}$ and a heightened sense of satisfaction derived from work. ${ }^{35}$ Some studies have also suggested that the availability and usage of ICT lead to higher levels of work engagement and decreased levels of exhaustion. ${ }^{9,36}$

Yet, for all the advantages associated with these technological advancements, literature abounds with disadvantages associated with technology explosion. These include working longer hours, ${ }^{37,38}$ blurring of the work and non-work boundaries, ${ }^{3,39}$ which affecting people's work-life balance, ${ }^{1,40}$ frequent interruptions and an accumulation of unanticipated tasks, ${ }^{41}$ increased stress because of work overload and a fear of losing control, ${ }^{7}$ and burnout. ${ }^{10}$ All of these can negatively impact people's health, both physiologically and psychologically.,42

These advantages and disadvantages associated with technology contain certain contradictions. For example, on the one hand, it is purported that ICT contributes to a sense of professional competence and control, thus enabling individuals to feel more autonomous in their work roles. However, frequent interruptions from emails and text messages, an accumulation of unforeseen tasks and the pressures associated with extending the working day can lead to a sense of losing control and feeling less in charge of one's work environment. These contradictions have given rise to certain paradoxes associated with the use of technology in the organisational setting. ${ }^{1,2,3,4,5,43}$ A paradox implies that the pursuit of specific goals is associated with actions that negate the goal. It contains elements and actions that are productive and counterproductive at the same time. These elements and actions, although contradictory, are inter-related and exist alongside one another. ${ }^{3}$

The eight paradoxes identified by Jarvenpaa and Lang 5 are seemingly the most widely cited. These paradoxes will be expounded upon in the following.

The empowerment/enslavement paradox: Information and communications technology has empowered users with new possibilities associated with the 'always on' nature 
thereof. People can access information and be in conversation with others irrespective of their location or time of day, and can therefore take charge and deal with situations in both professional and personal settings. Information and communication technologies enable higher productivity, provide more flexibility in work and allow for more efficient ways of coordinating people and work activities. Yet, the 'always on' nature of ICTs erases distance between people and diminishes certain freedoms that people hold dear. People fear that that they are being monitored more closely with ICTs and that there is no more separation of work and personal time. Furthermore, people feel pressured to respond to work-related communication, irrespective of when it comes through, which creates feelings of entrapment. Thus, for all the positives associated with the 'always on' nature of ICTs, people feel that it invades their privacy and erases the boundaries between work time and non-work time.

The independence/dependence paradox: Although technology allows for greater independence of the individual user to access information and communicate with others anytime and anywhere, the flipside is that users become dependent on the very idea of being connected, to the extent that being without a cellular phone, or even switching it off, is an unthinkable eventuality. People who are dependent on ICTs exhibit great discomfort with not being connected, as the anticipation of receiving an important message is overwhelming, and not answering a call or not immediately responding to a text message is seemingly a social taboo.

The fulfilling vs. creating needs paradox: Although ICTs have clearly fulfilled certain needs in society, they in turn give rise to a new set of demands, which in turn also creates new demands. It is thus a situation of 'the new solutions create even newer problems'. For example, for all the benefits ICTs provide with mobile banking, it has created a situation where online security is a major concern. In turn, mobile banking, as well as other sites (especially those that make provision for financial transactions), is incorporating more biometric access control measures, which in turn places more pressure on hardware manufacturers and app developers to incorporate biometric features into devices.

The competence/incompetence paradox: Information and communications technology has opened up a whole new set of competencies for users, allowing them to do things that were not possible in the past. However, in an effort to perform new tasks, or to perform known tasks more efficiently, people are often confronted with situations where the technology does not live up to expectation or turns out to be far more difficult to use than anticipated. This leads to a newfound sense of incompetence by users. Apart from these feelings of technological incompetence, Jarvenpaa and Lang ${ }^{5}$ also cite instances where ICTs diminished current competence. For example, users rely on electronic memory at the expense of their own memory (e.g. memorising telephone numbers), and predictive text diminishes people's spelling competence.
The planning/improvisation paradox: Although ICTs enable users to better plan and coordinate work activities, their diaries and social activities, it seems as though people are more reliant on technology and thus actually spend less time on these planning activities, as technology allows people to make up for a lack of planning through continuous improvisation. For example, instead of briefing invitees to a meeting properly as to the purpose of a meeting, people all too often just attach a plethora of attachments, which does not allow for proper preparation for a meeting. Also, being late for an appointment is far more acceptable, as a call or text message explaining the delay and rescheduling around this is deemed acceptable, often disguising basic bad planning.

The engaging/disengaging paradox: Although ICTs allow people to engage with anyone at any time and in any location, it also means that the engagement they are physically busy with needs to be broken off. Thus, to engage with the mobile device means disengagement with the physical setting. This disengagement from the physical setting through heightened online engagement is seen as detrimental, as it diminishes people's ability to interact face-to-face with other people.

The public/private paradox: Information and communications technology devices are seen as private tools enabling personal communication, and users are also able to set up their own private communication in the virtual realm which are free of physical or temporal constraints. Yet, private conversations and actions increasingly cross over into the public domain, creating friction between people and infringes upon people's privacy and basic freedom. In this regard, hearing only one side of a telephone call, or seeing a text message in isolation and out of context with accompanying messages by a spouse, for example, can create suspicion and confrontation, which could cause the person to take calls in private or delete text messages. Furthermore, there is also a tendency that people assume different roles in the physical and virtual worlds, exhibiting behaviours in the virtual realm that seem out of place in the physical one.

The illusion/disillusion paradox: This is closely associated with the competence/incompetence paradox and is associated with the promise presented by new hardware and apps. New technological offerings bring with them the allure of more capabilities. However, adoption of these new technologies often realises feelings of disappointment and disillusionment, as these new technologies do not live up to expectation. Think, for example, of the promise presented by the iPad before its release as a device that embodies the capabilities of both a mobile phone and a personal computer. However, people were soon disappointed by the fact that iPads to not support data storage devices such as CD-Rom or USB drives.

Although different researchers have presented a host of paradoxes, the work of Jarvenpaa and Lang ${ }^{5}$ seems the seminal point of departure from which other views on these paradoxes were borne. These paradoxes highlight some important contradictions regarding technology and ICT 
consumption in the modern era, and one could use these paradoxes as a point of departure to ascertain how technology impacts the 'goods' associated with work, as well as the impact technology has on the more common 'goods' that filter through into the workplace. To help highlight this, the discussion now turns to the ways in which technology and ICTs help sustain and enable the ideology of capitalism as the pervasive ideology that governs the way most organisations are managed.

\section{Technology and capitalism}

To fathom the moral nature of new workplace practices associated with technological proliferation and ICT usage, it would be prudent to first understand the ways in which this technological proliferation supports the ideals of capitalism. Capitalism, as we know it today, is the modern equivalent of the imperialist and colonialist projects that accompanied the Enlightenment era in Europe. In this era, certain institutions were created to oversee imperialist and colonial interests, such as the Dutch East India Company (VOIC - Vereenigde Oos Indische Companjie) and the British South Africa Company (BSCA). The first and second industrial revolutions witnessed the rise of capitalism, and associated with it, the growth of 'big business' which we are familiar with today.

To sustain themselves and to thrive, ideologies are dependent on artefacts and institutions that are created over time, and that entrench the ideology even further. Extreme examples of this are secret police units created under authoritarian regimes to subdue any form of dissidence amongst the populace, of which the most widely known are the Gestapo (Geheime Staatspolizei) in Nazi Germany and the Stasi (Staatssicherheitsdienst) in Communist East Germany. Although these are extreme examples that enforced and perpetuated ideologies through fear rather than more subtle forms of compliance, the fact is that these institutions and artefacts are needed in order to ensure the longevity of the ideology. They serve to enshrine the ideology and canvas support for it by means of portrayal of the victory of the said ideology over competing ideologies.

In terms of capitalism as an ideology, big corporations, business schools at universities, employer organisations and entrepreneurial success stories are the types of institutions and artefacts used to sustain and grow itself. Both the 'big-business' corporation and the entrepreneur are revered under capitalism and are seen as a manifestation of the capitalist ideal. Within the realm of the organisation, the managerial echelons have achieved a special status within capitalism as the professional 'elite'. Within capitalism, the basic factors of production (capital, natural resources, labour and management) have to work together in order for the business to be in a position to function properly and produce the products and services it has set out to produce, and to bring these products and services to market. This is associated with coordination of effort, a task ascribed to and overseen by management. It is also associated with cooperation between the factors, especially between the factors of capital, labour and management. This relation between management and labour within the capitalist project has been the subject of much scholarly endeavour, inciting interest from seminal scholars such as Marx, Foucault and Weber. $^{44}$

Karl Marx was of the opinion that this cooperation in a capitalist society is a forced relationship. He purports that the contract entered into between employee and employer is not a free contract, but driven by the canonisation of capital. ${ }^{45} \mathrm{He}$ argues that the employee is compelled to work out of necessity and has the liberty to contract as an equal in the labour market. This, in turn, brings into question the notion of the 'double interest of work', ${ }^{44}$ which posits that people work to pursue self-interest and that, through this selfinterest, they also engage in an endeavour to pursue the interests of the organisation. This 'double interest' is seen by some scholars to be simply untrue. ${ }^{44,46}$ Instead, Marx argues that this forced relationship sees employee and employer set against one another. This results in an incompatible, antagonistic hierarchical relationship between capital and labour, where capital deems it necessary to control labour in order to obtain value. ${ }^{44,45}$ This, in turn, becomes the defining characteristic of the employment relationship, and 'management' the tool to enforce such control. ${ }^{47}$

The employment relationship sketched above is not the only manifestation of this forced cooperation. This forced cooperation is also seen as a product of what Hanlon ${ }^{44}$ refers to as the 'disciplining necessity of the valorisation of capital'. This postulates that labour is brought together to produce something (i.e. products or services) that will lead to capital increasing itself. This is contrary to the notion that labour is congregated to produce something that satisfies a need in society, although this occurs as a consequence. Hanlon ${ }^{44}$ thus posits that profit drives this cooperation.

As profits are realised over time and capital increases, so too does the concentration of labour increase. In other words, as capital increases, the organisation increases the scope of its activities and more people are employed, thereby increasing the number of employees involved in this cooperation process. Yet, as Marx ${ }^{45}$ explains, this is also accompanied by labours' resistance to capital, as this cooperation increasingly seems like exploitation of the workforce. It also becomes apparent to labour that the necessary cooperation is not something they have autonomy over, but rather it is controlled by the owners of capital through the actions of the management corps.

Management, then, becomes pivotal in transforming individual ability into a unified corps of labour power. ${ }^{48}$ Along with this, management is also associated with integrating the efforts of labour power with the other forces of production to create surplus value for the owners of capital. 
What one is left with at the end of the day is a constant struggle between labour and capital, which is represented by management. Labour constantly rebels against management, feeling ever more entrapped and enslaved by a relationship that is by its very nature disparate. Management is continually focusing its efforts on controlling labour, stemming rebellion from the labour corps and maximising efficiency from labour. ${ }^{49}$ Thus, it is the control of labour that lies at the heart of the capitalist ideology. ${ }^{50}$ This control enables optimal integration of all available factors of production to create surplus value for the owners of capital.

With the argument highlighted above in mind, the attention shifts back to technology, and specifically ICTs, that has permeated our lives. To what extent does technology enable the capitalist control of labour? From the arguments presented so far in this article, the answer is a resounding: To a very large extent. Yet, the controlling character of technology implies an indirect and more subtle form of control to be exerted over individuals. Most prominent here is the empowerment/enslavement paradox as identified by Jarvenpaa and Lang. ${ }^{5}$ Technology enables greater work efficiency, thereby creating the illusion of being empowered, but ultimately technology enables management to enforce greater control over labour. Wearable and other self-tracking technologies (WSTT) are increasingly making their way into the work realm, thereby exerting greater - and in many cases overt - control over the workforce. ${ }^{51,52}$

The pervasiveness of the control inherent in this empowerment/enslavement paradox does not necessarily deter from the 'goods of work', ${ }^{12}$ as presented earlier in this article. Technology has a definite, positive contribution to make in terms of achieving excellence, contributing to society in general and the community in particular, thereby achieving recognition. For these 'goods of work', the lack of their presence is indicative of an ill of work, according to Gheaus and Herzog. ${ }^{12}$

However, when viewing the more common 'goods' that filter into the workplace, it is apparent that technology has the potential to enable capital, through management, to exert tremendous control over labour. The 'always on' culture that technology and ICT have brought with them, coupled with the blurring of work life and non-work life, the adoption of WSTTs, has led to a situation where control over the labour force is tantamount to total control, thus bordering on a state of domination over labour. The irony of this whole situation is that, more often than not, labour has welcomed this technological domination. Under the banner of advancement, increased efficiency and greater access to information, labour has adopted technology as the key to a better life. Yet, the very freedoms and advancements that lured labour to adopt these technologies in the first place have turned out to be the very things that enslave them even further..$^{53}$

As alluded to, technology has the propensity to exert a very subtle form of control, which, of course, would suite the owners of capital and their management corps perfectly. This is not a direct form of control where directives come from management and labour can identify the owners of capital, through management, as the focus of their dissatisfaction. Technology does not create the heightened control: it enables it. Yet, this only becomes apparent once the control has already been tightened. ${ }^{52}$ This makes technology a precarious tool. As a mechanism to tighten control over labour, it totally disrespects people's free-time and leisure time, and shows little regard for people's right to non-domination and selfdetermination. Furthermore, it has also not been very respectful of people's psychological health. ${ }^{49,52}$

In the hands of the owners of capital, technology can be seen as a dangerous tool. It enables subtle forms of control, manipulation and domination which violate people's basic freedoms. However, many of these actions are totally acceptable from the perspective of the owners of capital, citing operational efficiencies, the importance of the work task, impending deadlines and other economic arguments as justification for these violations. ${ }^{54,55}$ This, in turn, leads to a very important question. Aspects such as respect for people's health (both physiological and psychological), the right to self-determination and non-domination, the respect for people's free-time and leisure time are basic personal freedoms that ought to be respected. Any violation of these basic freedoms could be viewed as something that is morally questionable. Yet, the organisational justifications are argued to be acceptable where such infringements occur in the name of work.

In the light of this, the question is, 'does economic reasoning take precedence over moral reasoning'? In my view, even the mere postulation of this question is vulgar. Economic reasoning should always be subservient to moral reasoning. Any attempt to reason otherwise is simply not acceptable in my view. Capitalism has always tried to frame itself as 'something different' by coining trite phases such as 'business is business', 'when it comes to business, things are different' or 'business does not work like that'. To suggest that business and capitalism represent a different form of morality, and that business decisions or actions should be judged separately is arrogant beyond conception.

\section{Workplace implications}

This argument thus far has exposed some pertinent issues associated with technological proliferation in times where we are trying to make sense of 4IR. Most importantly, the argument has shown that the empowerment/enslavement paradox of Jarvenpaa and $\mathrm{Lang}^{5}$ is very real and, as technological proliferation continues, will become ever more pervasive. This paradox substantiates the Marxist notion of control over the labour force, and has the propensity to take this control to the extreme, even to near slavery. However, this subjugation is so subtle that it is almost welcomed by individuals. 
The argument as presented in this article is a definite call for a heightened focus on work-life balance. All organisations seemingly hold their 'human resources' in high regard. The COVID-19 pandemic has even seen organisations calling their employees 'superheroes'. If this is indeed what the organisation believes - in contrast to merely paying lip service for the purpose of positive public sentiment to boost sales, or share prices - then they need to put their money where their mouths are, and do it sincerely. A good place to start would be organisational guidelines on how to govern communication and ICT usage outside of working hours, and what type of communication is acceptable and permissible. However, it is imperative that workers have a voice in this process; otherwise, the potential for exploitation is blatantly apparent. Companies like BMW and Volkswagen have done exactly that, and have implemented policies limiting access to e-mail and discouraging texting on social media platforms outside of office hours to enhance employee well-being. These types of steps have also been encouraged on a broader, community level (e.g. in Germany and France). ${ }^{56,57}$

As we forge ahead in the technological era, it is apparent that not only the 4IR discourse, but also organisations that operate within this space need to grapple increasingly with the effects of technological proliferation on people, how this impacts their basic freedoms and what steps role-players are going to take to ensure that work-life balance is maintained. All too often, we stare ourselves blind against technology when speaking about 4IR, but the emphasis needs to shift to people and the role they play in this era.

\section{Concluding remarks}

As the 4IR surges ahead, it is imperative that the advantages that can be gained through technology proliferation will be offset by the disempowering effects of this very same technology. This is a much more subtle subjugation than the blatant workplace domination and exploitation witnessed during the first and second industrial revolutions. It is more subtle because the very allure thereof is what ultimately turns out to be the entrapment and ultimate control on the part of the owners of capital. Much like the Eagles lament in 'Hotel California': 'We are all just prisoners here of our own device. ${ }^{\prime 58}$

Yet, as we grapple with the reality of what the nature of society, business and the workplace will look like in a post COVID-19 world, it has become all too apparent during the COVID-19 pandemic just how undervalued labour is (and in the context of COVID-19, especially labour providing essential services). What is essential is that the value of labour needs to be emphasised through activism, whatever form that might assume. Capital needs to respond to such activism with a less repressive and a more cooperative stance.

What is needed is for capital, labour, management and technology need to come together for heightened cooperation in the 'new world' we are in. Egotistic self-interest, especially on the part of capital, does not seem to be a virtue that will be celebrated any longer.

\section{Acknowledgements Competing interests}

The author has declared that no competing interest exists.

\section{Author's contributions}

I declare that I am the sole author of this research work.

\section{Ethical consideration}

This article followed all ethical standards for a research.

\section{Funding information}

This research received no specific grant from any funding agency in the public, commercial or not-for-profit sectors.

\section{Data availability statement}

The authors confirm that the data supporting the findings of this study are available within the article.

\section{Disclaimer}

The views and opinions expressed in this article are those of the author and do not necessarily reflect the official policy or position of any affiliated agency of the author.

\section{References}

1. Schlachter S, McDowall A, Cropley M, Inceoglu I. Voluntary work-related technology use during non-work time: A narrative synthesis of empirical research and research agenda. Int J Manage Rev. 2018;20(1):825-846. https://doi. and research agenda.
org/10.1111/ijmr.12165

2. Putnam LL, Myers KK, Gailliard BM. Examining the tensions in workplace flexibility and exploring options for new directions. Hum Relat. 2014;67(1):413-440. https://doi.org/10.1177/0018726713495704

3. Ter Hoeven $\mathrm{CL}$, Van Zoonen W, Fonner, KL. The practical paradox of technology: The influence of communication technology use on employee burnout and engagement. Commun Monogr. 2016;83(2):239-263. https://doi.org/10.1080/03 637751.2015.1133920

4. Mazmanian M, Orlikowski WJ, Yates J. The autonomy paradox: The implications of mobile email devices for knowledge professionals. Organ Sci. 2013;24(1): 1337-1357. https://doi.org/10.1287/orsc.1120.0806

5. Jarvenpaa SL. Lang KR. Managing the paradoxes of mobile technology. Inf Syst Manage. 2005;22(4):7-23. https://doi.org/10.1201/1078.10580530/45520.22.4. 20050901/90026.2

6. Tenakoon KLUS. Empowerment or enslavement: ICT use and work-life balance of managers and professionals. PhD thesis. Calgary: University of Calgary; 2011.

7. Barley SR, Meyerson DE, Grodal S. E-mail as a source and symbol of stress. Org Sci. 2011;22(4):887-906. https://doi.org/10.1287/orsc.1100.0573

8. Cavazotte F, Lemos AH, Villadsen K. Corporate smart phones: Professionals' conscious engagement in escalating work connectivity. New Technol Work Employ. 2014;29(1):72-87. https://doi.org/10.1111/ntwe.12022

9. Nahrgang JD, Morgeson FP, Hofmann DA. Safety at work: A meta-analytic investigation of the link between job demands, job resources, burnout, engagement, and safety outcomes. J Appl Psychol. 2011;96(1):71-94. https://doi. org/10.1037/a0021484

10. Bakker AB, Demerouti E, Sanz-Vergel Al. Burnout and work engagement: The JD-R approach. Ann Rev Org Psychol Org Behav. 2014;1(1):389-411. https://doi. org/10.1146/annurev-orgpsych-031413-091235

11. Yeoman R. Meaningful work and workplace democracy (PhD thesis). London: University of London; 2014.

12. Gheaus A, Herzog, L. The goods of work (other than money!). J Soc Philos 2016;47(1):70-89. https://doi.org/10.1111/josp.12140

13. Arneson R. Meaningful work and market socialism. Ethics. 1987;97(3):517-545. https://doi.org/10.1086/292864

14. Yeoman R. Conceptualising meaningful work as a fundamental human need. J Bus Ethics. 2014;125(2):235-251. https://doi.org/10.1007/s10551-013$1894-9$ 
15. Murphy JB. The moral economy of labor: Aristotelian themes in economic theory. New Haven, CT: Yale University Press; 1993.

16. McIntyre A. After virtue. A study in moral theory. Notre Dame: University of Notre Dame Press; 1984.

17. Csikzentmihalyi M. Beyond boredom and anxiety: Experiencing flow in work and play. San Francisco, CA: Jossey-Bass; 2000.

18. Pink D. Drive: The surprising truth about what motivates us. New York, NY Riverhead Books; 2011.

19. Schwartz T, Porath C. The power of meeting your employees' needs. Harv Bus Rev. 2014;26(6):442-457

20. Terkel S. Working: People talk about what they do all day and how they feel about what they do. New York, NY: The New Press; 1974.

21. Francis J, Giles-Corti B, Wood L, Knuiman M. Creating sense of community: The role of public space. J Environ Psychol. 2012;32(4):401-409. https://doi. org/10.1016/j.jenvp.2012.07.002

22. Estlund C. Working together: How workplace bonds strengthen a diverse democracy. New York, NY: Oxford University Press; 2003.

23. MacMahon C. Authority and democracy: A general theory of government and management. Princeton, NJ: Princeton University Press; 1994.

24. Honneth A. Freedom's right: The social foundations of democratic life. New York, NY: Columbia University Press; 2014.

25. Isaacson W. Einstein: His life and universe. New York, NY: Simon and Schuster; 2007.

26. Gosling FG. The Manhattan Project: Making the atomic bomb. Washington, DC: U.S. Department of Energy; 2010.

27. Moriarty J. Rawls, self-respect, and the opportunity for meaningful work. Soc Theory Pract. 2009;35(3):441-459. https://doi.org/10.5840/soctheorpract200935325

28. Ciulla JB. The working life: The promise and betrayal of modern work. New York, NY: Random House; 2000

29. Roessler B. Meaningful work: Arguments from autonomy. J Polit Philos. 2012;20(1):71-93. https://doi.org/10.1111/j.1467-9760.2011.00408.x

30. FrankI VE. The unheard cry for meaning: Psychotherapy and humanism. New York, NY: Simon and Schuster; 1978

31. Wolf S. Meaning in life and why it matters. Princeton, NJ: Princeton University Press; 2010.

32. Perlow L. Sleeping with your smartphone: How to break the $24 / 7$ habit and change the way you work. Boston, MA: Harvard Business Review Press; 2012.

33. ITU. Measuring digital developments: Facts and figures 2019 [homepage on the Internet]. 2020 [cited 2020 Apr 14]. Available from: https://www.itu.int/en/ ITU-D/Statistics/Pages/facts/default.aspx

34. Matusik SF, Mickel AE. Embracing or embattled by converged mobile devices? Users' experiences with a contemporary connectivity technology. Hum Relat. 2011;64(1):1001-1030. https://doi.org/10.1177/0018726711405552

35. Diaz I, Chiaburu DS, Zimmerman RD, Boswell WR. Communication technology: Pros and cons of constant connection to work. J Vocat Behav. 2012;80(1):500-508. https://doi.org/10.1016/j.jvb.2011.08.007

36. Ten Brummelhuis LL, Bakker AB, Hetland J, Keulemans L. Do new ways of working foster work engagement? Psicothema. 2012;24(1):113-120.

37. Guest DE. Perspectives on the study of work-life balance. Soc Sci Inf Stud. 2002;41(2):255-279. https://doi.org/10.1177/0539018402041002005
38. Derks D, Bakker, AB. Smartphone use, work-home interference, and burnout: A diary study on the role of recovery. Appl Psychol. 2014;63(1):411-440. https:// doi.org/10.1111/j.1464-0597.2012.00530.x

39. Boswell WR, Olson-Buchanan JB. The use of communication technologies after hours: The role of work attitudes and work-life conflict. J Manage. 2007;33(4):592-610. https://doi.org/10.1177/0149206307302552

40. Chesley N. Blurring boundaries? Linking technology use, spillover, individual distress and family satisfaction. J Marriage Fam. 2005;67(Dec):1237-1248. https://doi.org/10.1111/j.1741-3737.2005.00213.x

41. Fonner KL, Roloff ME. Testing the connectivity paradox: Linking teleworkers' communication media use to social presence, stress from interruptions, and organizational identification. Commun Monogr. 2012;79(1):205-231. https://doi. org/10.1080/03637751.2012.673000

42. Crawford ER, LePine JA, Rich BL. Linking job demands and resources to employee engagement and burnout: A theoretical extension and meta-analytic test. J App Psychol. 2010;95(1):834-848. https://doi.org/10.1037/a0019364

43. Leonardi PM, Treem JW, Jackson MH. The connectivity paradox: Using technology to both decrease and increase perceptions of distance in distributed
work arrangements. J Appl Commun Res. 2010;38(1):85-105. https://doi. org/10.1080/00909880903483599

44. Hanlon G. The dark side of management: A secret history of management knowledge. New York, NY: Routledge; 2016.

45. Marx K. Capital: A critique of political economy, vol. I. Harmondsworth: Penguin 1976.

46. Roediger D, Esch E. The production of difference: Race and the management of labour in US history. Oxford: Oxford University Press; 2012.

47. Banaji J. The fictions of free labour: Contract, coercion, and so called unfree labour. Historical Materialism. 2003;11(3):69-95. https://doi.org/10.1163/ 156920603770678319

48. Federici S. Caliban and the witch: Women, the body and primitive accumulation. New York, NY: Autonomedia; 2004.

49. Berardi F. The soul at work: From alienation to autonomy. New York, NY: Semi text(e); 2009

50. Deleuze G. Postscript on the societies of control. October. 1992;59(1):3-7.

51. Chan J, Pun N. Suicide as protest for the new generation of Chinese migrant workers: Foxconn, Global Capital, and the state. Asia Pac J. 2010;37(2):1-50.

52. Moore $P$, Robinson A. The quantified self: What counts in the neoliberal workplace. New Media Soc. 2016;18(11):2774-2792. https://doi.org/10.1177/14614448 15604328

53. Raunig G. A thousand machines. Cambridge: MIT Press; 2010.

54. Kirkpatrick G. Critical technology: A social theory of personal computing. Aldershot: Ashgate; 2004

55. Rolnik S. The geopolitics of pimping. In: Raunig G, Ray G, Wuggenig U, editors. Critique of creativity: Precarity, subjectivity and resistance in the 'creative Critique of creativity: Precarity, subjectivity
industries'. London: MayFly, 2011; p. 23-40.

56. Anderson LV, Griswold A, McIntyre A. No, France did not bar workers from answering emails after 6 p.m. Moneybox [homepage on the Internet]. 2014 [cited 2020 Apr 17]. Available from: http://www.slate.com/blogs/moneybox/2014/04/10/debunked france_did_not_just_ban_workers_from_answering_emails_after_hours.html

57. Vasagar J. Out of hours working banned by German Labour Ministry. The Telegraph [newspaper online]. 2013 Aug 30 [cited 2020 Apr 18]. Available from: https:// www.telegraph.co.uk/news/worldnews/europe/germany/10276815/Out-ofhours-working-banned-by-German-labour-ministry.html

58. Felder, D, Frey, G and Henley, D. 1976. Hotel California. Los Angeles: Asylum Records. 